\title{
Stabilization Measure Adopted for Controlling Landslide: A Case Study of Upper Mai Hydroelectric Project
}

\section{Kanchan Chaulagai}

Abstract: Stability is the key issue in landslide stabilization. Methodology and component adopted in stabilizing the slide play vital role in this regards. In many occasion, stability measure adopted for controlling slide has been found to be unsuccessful, inadequate causing not only the safety risk but also huge economic loss. This paper describe history, effects, causes, stabilization measures and effectiveness of these measures played for controlling landslide of headwork area of Upper Mai Hydroelectric Project. The pioneering solution applied for landslide stabilization such as application of rock bolts, shotcrete and water management found to be highly effective in controlling the landslide.

Keywords: Landslide, geology, stabilization measure, structural supports

\section{Introduction}

$\mathrm{T}$ he Himalayan regions are characterized by extremely steep and rugged slopes with frequent landslides occurring during monsoon seasons. In every monsoon period, small and large scale slide occurs causing huge damage in lives in these regions, property, infrastructure and environments. Stabilizing landslide in the Himalayan regions has become most challenging work for all stakeholders and concerned parties especially Government, Road Department, planners, developers, engineers, geologists and contractors, who are directly or indirectly involved in stabilization measure either for construction of roads, highways and hydropower projects in hilly regions.

Pre and Post hill slopes stability measure has been adopted in national infrastructures such as roads, bridges, dams, and hydropower stations. In most of the cases, the stabilization measure adopted for protection of the slide slope has been found to be conventional types that include retaining structure with water management. Application of retaining structure for protection of slide slope in many cases was found to be inadequate and insufficient.

In this context, this paper describes a complete post sliding measure that was adopted in headwork area of Upper Mai Hydroelectric Project (UMHEP) to stabilize a slide. During excavation, preventive measures were adopted to prevent failure of the hill slope at the settling basin of UMHEP. These include construction of gabion walls at the toe of the slopes and trimming hill slope to standard slopes. However, these preventive measures did not survive a monsoon season. To overcome this situation, application of rock bolts, shotcrete along with water management had been adopted for stabilizing the slide slope.

\section{Upper Mai Hydroelectric Projects}

The Upper Mai Hydroelectric Project is a run-of-river (RoR) type project located in Mabu Village Development Committee of Ilam District in Nepal. Geographically, the project is located between latitude $27^{\circ} 06^{\prime} 15^{\prime \prime}$ and $27^{\circ} 3^{\prime} \mathrm{O}^{\prime \prime}$ north and longitude $87^{\circ} 53^{\prime} 30^{\prime \prime}$ and $88^{\circ} 01^{\prime} 15^{\prime \prime}$ east and lies at an elevation of $1600 \mathrm{~m}$ (Upper Mai Hydroelectric Project, Design Report, 2009). Mai Khola is monsoon as well as spring fed perennial river. It originates from the Mahabharata range at 3586.0 m altitude and flows north to south. The same river Mai is named Kankai Khola when it enters Jhapa district. Almost 60\% of its total drainage area lies in Ilam district.

The installed capacity of UMHEP is $9.98 \mathrm{MW}$ and generates $57.78 \mathrm{GWh}$ energy per annum. To generate this energy, water has to pass total $4.2 \mathrm{~km}$ of waterway including Headrace Pipe, Headrace Tunnel, Penstock pipe and Tailrace cannel. Headwork structure and 75\% of headrace pipe lies in the right bank of Mai Khola where as other structure headrace tunnel, penstock pipe, powerhouse and tailrace cannel lies in the left bank. The design discharge of the project is $3.88 \mathrm{~m}^{3} / \mathrm{s}$ at $32.52 \%$ exceedance flow.

The main focus of this paper is to highlight the stabilization measures adopted in the hill slope of the headwork area.

\section{General Geology of the Project Area}

The project area, geologically, is located approximately $20 \mathrm{~km}$ north of Main Central Thrust (MCT) and $30 \mathrm{~km}$ southeast of Tamar Khola Thrust according to Geological Surface Mapping of Nepal, and lies in the Higher Himalayan succession (Fig.1). The geology of the region is dominated by the Precambrian to Cambrian kyanite and sillimanite bearing gneisses, biotite schist, metaquartzite, amphibolite, calcsilicate gneiss, ortho-gneiss and augen gneiss. However, the lithology of the projects area is comprised of medium to coarse grained, thickly to very thickly foliated, medium strong mica-schist, gneiss, schistose gneiss and medium to coarse grained, thinly to thickly foliated, weak to medium strong schist, garnetiferous muscovite-boitite-Quartz schist of Precambrian age. 


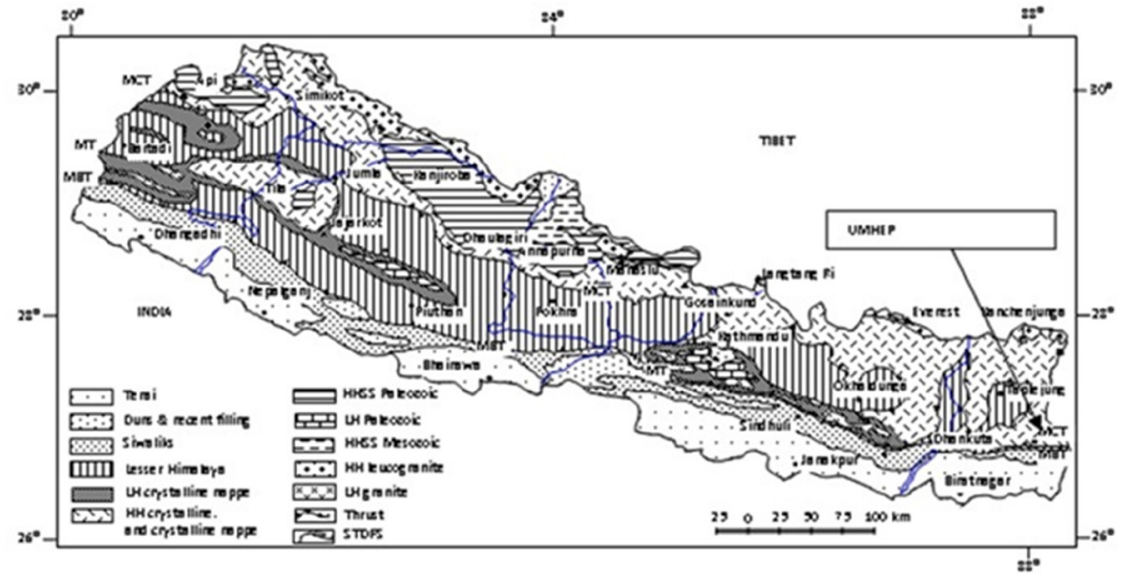

Figure 1: Geological Surface Mapping of Nepal (After Upreti and Le Fort, 1999)

\section{Geology of the Slide Area}

The slide zone consists of colluvial material underlain by gneiss rock mass. The colluvial material consists of boulders, gravel, sand and fine. The coarse fragments of colluvial material are of schist and gneiss. The underlain gneiss is light grey, fresh to slightly weathered, moderately to thickly foliated, medium to coarse grained, medium strong. The slope of slide area is gentle to moderately steep.

Flat to gentle alluvial terrace exist at the toe of the hill slopes/Slide area. The alluvial deposit consists of silt, sand, gravel, cobble and boulders of gneiss and schist. The maximum diameter of the boulder is about $1.5 \mathrm{~m}$.

\section{Landslide in Headworks}

Landslide is the most common natural phenomenon occurring in Himalayan regions. Many factors are responsible for causing landslide in this region. The factor may be either internal or external. Until and unless these factor changes, the slope of the hill remain the same. As there goes some changes in these two factors, the hill slope cannot retain in its own form, but have to reform into new state.

Several internal and external factors are responsible directly or indirectly for slope instability. Not only may the present factor, past factor also play the vital role for the cause of instability. Factors responsible for instability are strength of rock and soil, its structure, porosity, weathering condition and permeability. Similarly, seismicity, intensity of precipitation, land use patterns, natural slope conditions and groundwater conditions are also reasonable causes for instability.

For the construction of settling basin at the right bank of Mai Khola, toe portion of the hill slope has to be cut. Since having adequate space at the river bank, the designer has shifted the structure towards the hill slope ignoring the 2D Electrical Resistivity Tomography (ERT) forecast. ERT report had recommended not cutting the toe of the slope for the construction of settling basin. If the slope has to be cut, retaining structures should be constructed for the stability. As structure lies near the hill slope, second recommendation has to be adopted. The rock mass encounter at the base of settling basing near the toe of hill slope was very hard hence PC 200 excavator with breaker was used for chiseling the rock mass. The breaker was not sufficient for the chiseling because of very hard rock mass so continuous blasting was carried out to get the desire depth for the base part construction of settling basin.

Application of gabion wall as a retaining structure was insufficient for the protection of hill slope after its toe cutting. Hence, the slide occurred (Photo.1) causing huge damage in the structure near its toe area, ultimately hampering in project completion time and cost. Since this paper focuses on the protection work for its stability; it will not discuss in detail the possible causes of the landslide.

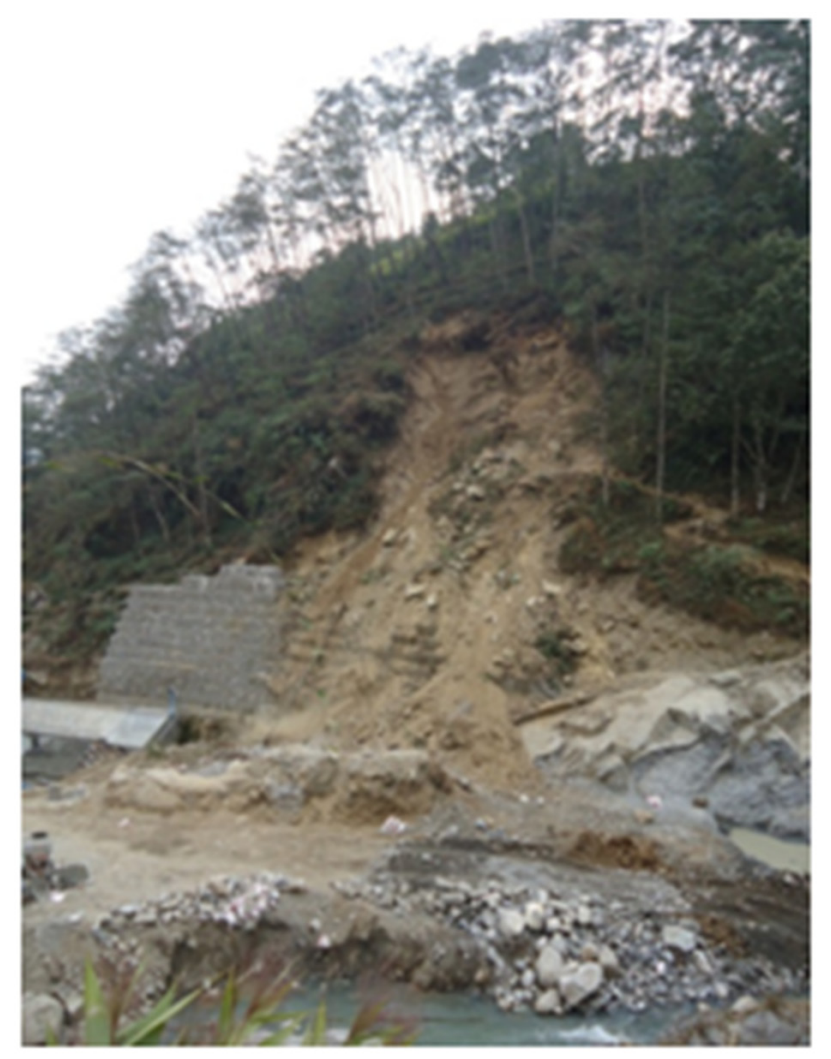

Photo 1: Landslide at Headwork's Area.

\section{Stabilization Measure}

Geophysical investigation carried out during the detail designed phase was highly ignored while setting out the location of settling basin. However, second recommendation was tried to be adopted, but it was 
found to be inadequate. In this section, we will not discuss the reasons for the failure of retaining structure, which was applied for the protection of hill slope. Thus, this section mainly cover post sliding measure including earth work, water management and structural support measure carried out in landslide in headwork area of Upper Mai Hydroelectric Project.

\section{Earthworks}

Removal of unstable soil or rock mass at the upper part of the slide is the beginning/basic procedure for the stabilization of the slide. In UMHEP, all the loose soils, detached blocks located at the upper part of the slide were removed to reduce the load and shear force (Photo 2). Removing of unstable materials was continued from top to the bottom of the slide. During the removal process fractured, cracked rock mass was chiseled and gradient of the slope was maintained to standard slope gradient.

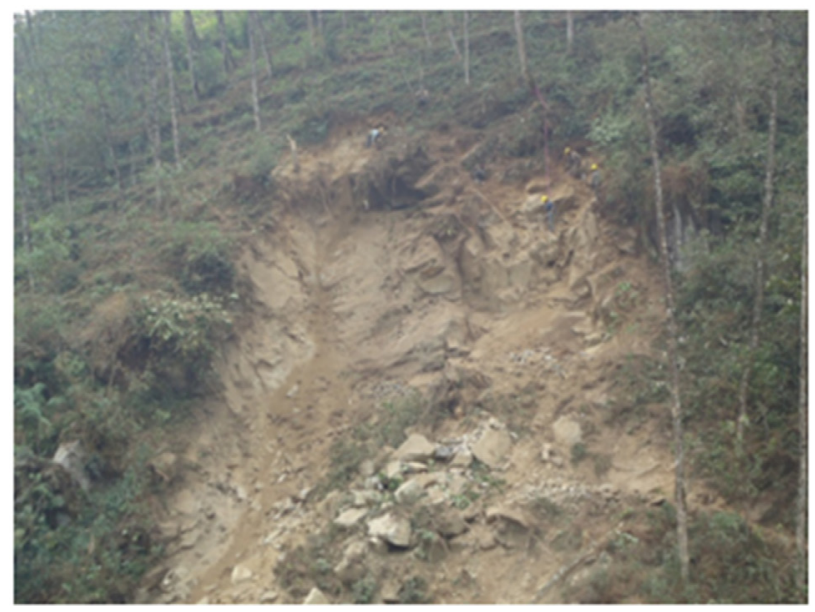

Photo 2: Removing loose material from top of landslide

\section{Water Management}

Drainage management play vital role in controlling the landslide. Management of drainage networks alone significantly improves the stability of the slide (Adhikari, 2001). Water management is a primary control measure for controlling the slide. Water management in the slope consists of surface and sub-surface drainage that are capable to take away the water to natural drainage system.

\section{Surface Drainage}

The surface drainage of the slide area is one of the most important control measures (Kuberan et al., 1993). Trapezoidal Stone Masonry Catch drain was constructed $5 \mathrm{~m}$ above the head of the landslide to prevent the infiltration of surface runoff water and rainfall water, which ultimately increases the pore water pressure in the slide zone. The size of the catch drain was $30 \mathrm{~cm}^{*} 30$ cm which was designed to accommodate surface runoff for a precipitation intensity of a once in 50 years. The position of the catch drain and direction of water flow was fixed according the site condition and feasibility for the construction of drain. The end of the drain was connected with the natural drainage system for its safe discharge.

\section{Sub Surface Drains}

Raising and falling phenomenon of groundwater table usually happened in dry and wet seasons which will ultimately affects the stability of the slope. A $2 \mathrm{~m}$ long, $36 \mathrm{~mm}$ diameter weep holes were constructed at stagger pattern in the slide area at $2 \mathrm{~m} \mathrm{c} / \mathrm{c}$ for lowering the groundwater table and for decreasing the pore water pressure acting beyond the rock mass.

\section{Structural Supports}

Structural supports play key role in stabilizing the slide by increasing the stabilizing component necessary for the sliding mass (Adhikari, 2001). Various components of structural supports were used in slide area of Upper Mai Hydroelectric Project (Photo.2).

\section{Retaining Wall}

Gabion wall has been built along the hill slope for the toe protection. Extra one layer of gabion wall has been added so that it would act as a barrier for sliding material coming from the hill slope moving toward the settling basin. It also retains the sliding material until its open space is filled. It is constructed in rear stepped type with front batters (inwards inclination) of 1:8 anchored to the foundation, where bedrock is encountered at the base. For proper drainage system, weep holes has been constructed in the gabion wall at its base. The Geomembranes were placed all around the drain, backward side and at the base of gabion wall to prevent transportation of fine particles with water. Gabion wall was constructed according to the Indian Standard code.

\section{Rock Bolts}

After removing all the loose material from the slide area, the exposed surface was anchored with the rock bolts of $3 \mathrm{~m}$ long, $25 \mathrm{~mm}$ diameter at stagger pattern at $2 \mathrm{mc} / \mathrm{c}$. The exposed surface was highly fractured and loose hence $5 \mathrm{~m}$ long, $25 \mathrm{~mm}$ diameter at stagger pattern at $2.5 \mathrm{mc} / \mathrm{c}$. was recommended (Upper Mai Hydroelectric Project, Tunnel Inspection Report, 2013) but due to unavailability of drilled machine of required length, the drilled hole length and spacing was confined to $3 \mathrm{~m}$ and 2 $\mathrm{mc} / \mathrm{c}$. The rock bolts were inserted in pattern manner in the slide area, in the area of possibilities of future plane failure and wedge failures additional numbers of rock bolts were also inserted for extra safety since the length of rock bolts had been confined to $3 \mathrm{~m}$. In some of the hole, the desired length was still not received due to highly fracture and open jointed rock mass, the length of the rock bolts in such holes were confined to the obtain length.

\section{Shotcrete}

Shotcrete can be applied by two distinct application techniques, the dry-mix process and the wet-mix 
process. Decisions to use the dry or wet mix shotcrete process are usually made on a site-by-site basis. Due to the inaccessibility of site for transportation and also equipment available at the site of contractor, dry mix system was adopted.

Rock mass condition of the slide area was not so good, it was very loose, open jointed so Mesh reinforced shotcrete was adopted for stabilizing slopes (Photo 3). Weld mesh made from $4 \mathrm{~mm}$ diameter wire welded into a $100 \mathrm{~mm} \times 100 \mathrm{~mm}$ grid was used. Since, it is strong enough and the sheets are light enough to handle. Weld mesh was tightly pinned against the rock face and anchored with rock bolts. Before applying shotcrete to the surface, the work area was sprayed with an air-water jet to remove loose rock and dust and then later plain shotcrete was applied over it. The final stabilization of the slide is shown in Photo 4.

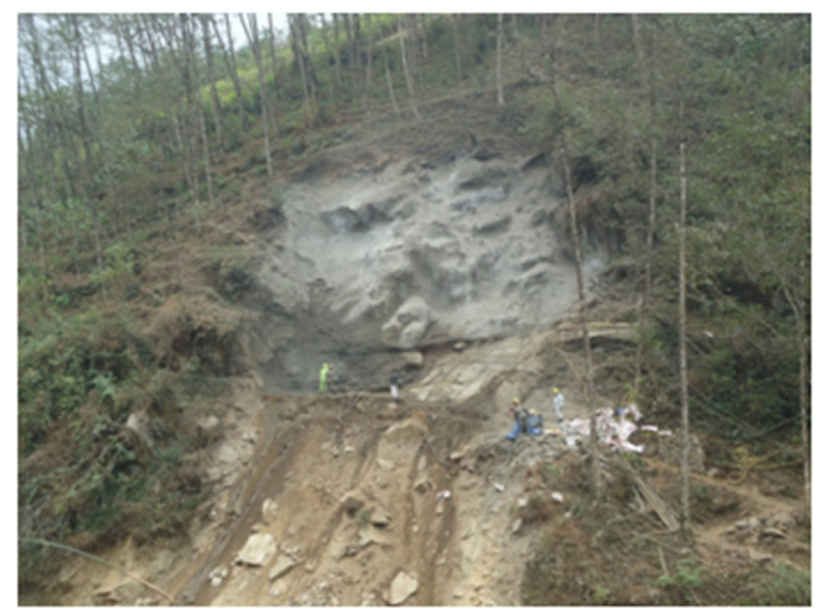

Photo 3: Application of shotcrete on slope

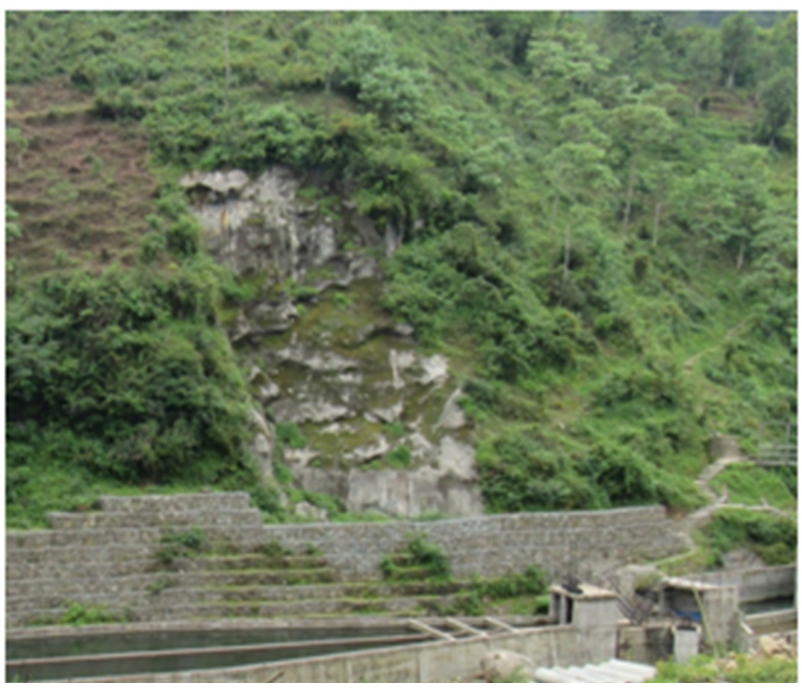

Photo 4: Stabilization of slide

\section{Conclusion}

Stabilization measure adopted for protection of the slide slope with conventional type always does not give successful results. The pioneering solution applied for landslide stabilization such as application of rock bolts, shotcrete and water management is found to be highly effective in controlling the slide of Upper Mai Hydroelectric Project.

The Upper Mai HEP case also illustrates that application of rock bolts, shotcrete in landslide area is not easy task, and its cost is very high comparing to other stability measures that were generally applied.

Kanchan Chaulagai hold Master degree in Engineering Geology from Tribhuvan University, (2007). He has over nine years of experience in design, construction supervion and planning of tunneling in Nepal Himalaya from Far Wastern Region to Eastern Region. He works as a Tunnel Manager in Panchakanya Mai Hydropower Limited.

Corresponding E-mail: kanchan_chaulagai@yahoo. com

\section{References}

Adhikari, T. 1., 2001, Landslide control and stabilization measures for mountains roads: A case study of arniko highway, central Nepal. In: Tianchi, Li., Chalise, S.R., Upreti, B.N.(Eds.), Landslide hazard mitigation in Hindu KushHimalayas, ICIMOD, pp.263-289.

Kuberan. K., Dev. N., Gupta. S. L., 1993, State of the practice report on control measures for landslides, Central Soil and Materials Research Station, pp.7-8.

Mai Valley Hydropower Private Limited, 2009, Upper Mai Hydroelectric Project (9.98 MW): Design Report, Volume 1- Main Report, pp. 21-41.

Mai Valley Hydropower Private Limited, 2013, Upper Mai Hydroelectric Project: Tunnel Inspection Report, pp.14-17. 